\title{
An environmental cost-benefit analysis of alternative green roofing strategies
}

\author{
Reshmina William ${ }^{\mathrm{a}}$, Allison Goodwell ${ }^{\mathrm{a}}$, Meredith Richardson ${ }^{\mathrm{a}}$, Phong V. \\ V. Le ${ }^{\mathrm{a}}$, Praveen Kumar ${ }^{\mathrm{a}, \mathrm{b}, *}$, Ashlynn S. Stillwell ${ }^{\mathrm{a}}$, \\ ${ }^{a}$ Department of Civil and Environmental Engineering, University of Illinois, Urbana, IL \\ 61801, USA \\ ${ }^{b}$ Department of Atmospheric Sciences, University of Illinois, Urbana, IL 61801, USA
}

\begin{abstract}
Green roofs and cool roofs are alternative roofing strategies that mitigate urban heat island effects and improve building energy performance. Green roofs consist of soil and vegetation layers that provide runoff reduction, thermal insulation, and potential natural habitat, but can require regular maintenance. Cool roofs involve a reflective layer that reflects more sunlight than traditional roofing materials, but require additional insulation during winter months. This study evaluates several roofing strategies in terms of energy performance, urban heat island mitigation, water consumption, and economic cost. We use MLCan, a multi-layer canopy model, to simulate irrigated and non-irrigated green roof cases with shallow and deep soil depths during the spring and early summer of 2012, a drought period in central Illinois. Due to the dry conditions studied, periodic irrigation is implemented in the model to evaluate its effect on evapotranspiration. Traditional and cool roof scenarios are also simulated by altering surface albedo and omitting vegetation and soil layers. We find that both green roofs and cool roofs significantly reduce surface temperature compared to the traditional roof simulation. Cool roof temperatures always remain below air temperature and, similar to traditional roofs, require low maintenance. Green roofs remain close to air temperature and also provide thermal insulation, runoff reduction, and carbon uptake, but might require irrigation during dry periods. Due to the longer lifetime of a green roof compared to cool and traditional roofs, we find that green roofs realize the highest long term cost
\end{abstract}

\footnotetext{
${ }^{*}$ Corresponding author

Email address: kumar1@illinois.edu (Praveen Kumar)
} 
savings under simulated conditions. However, using longer-life traditional roof materials (which have a higher upfront cost) can help decrease this price differential, making cool roofs the most affordable option due to the higher maintenance costs associated with green roofs.

Keywords: Green roofs, cool roofs, energy costs, ecohydrology

\section{Introduction}

The emergence of highly urbanized landscapes has led to a plethora of environmental problems such as increased storm runoff, degraded water and air quality, high building energy use, and the urban heat island (UHI) effect. Green building standards incentivize passive technologies that reduce the energy and environmental footprint of structures [1] and mitigate many of these problems. One simple strategy to improve building energy efficiency is to increase roof thermal insulation. Cool roofs and green roofs are alternative methods that also promote the natural reduction of air temperatures during the summer months. Cool roofs involve a highly reflective layer [2] to reflect incoming radiation and absorb less heat than a conventional roof, while a green roof is a rooftop with a planting medium and partial to complete vegetation coverage [3]. There are various trade-offs involved in the implementation of either alternative roofing strategy in terms of building energy efficiency, UHI effect reduction, cost, and other environmental concerns such as water consumption and runoff reduction. Particularly for green roofs, performance is highly dependent on seasonal climate variability and vegetation composition $[4,5]$, and must be assessed on a regional basis. We introduce a detailed modeling approach to compare performance and trade-offs between green roofs, cool roofs, and traditional roofs during a dry spring and summer season in central Illinois.

Cool roofs have similar installation and maintenance costs as traditional roofs, and effectively reduce rooftop temperatures in hot climates. However, they can increase energy costs in colder climates due to their decreased heat absorption capacity [2], and must be combined with added insulation to keep buildings warm during the winter [6]. Green roofs have multiple benefits, making them an attractive solution for many issues facing urban areas. Similarly to cool roofs, green roofs can significantly reduce the UHI effect [4, 6-9] due to increased reflectivity. In addition to reducing ambient air temperatures in hot climates, the soil and vegetation layers of green roofs provide natural insulation that mitigates short-term fluctuations in air temperature [8]. This natural insulation leads to reduced building cooling 
requirements during the summer and reduced heating during the winter [9]. Finally, rooftop vegetation can increase biodiversity [10], improve air quality through leaf carbon uptake, and reduce stormwater runoff [11]. Plant species are typically chosen to be drought resistant and have shallow taproots [12], and include sedums, other succulents and local native species [13, 14]. A potential disadvantage of green roofs is the moisture requirement for plant species during dry periods. Water availability dictates soil moisture and vegetation health, which both impact the cooling or insulating properties of the rooftop $[5-7,11]$. Depending on plant species, soil depth, and water retentive properties, a green roof might require added maintenance and irrigation during drought periods.

Recent studies include analysis of green or cool roof thermal properties $[6,7,15-17]$, hydrologic characteristics $[11,18]$, or the impact of moisture conditions on thermal properties [5]. In most studies, the vegetation canopy layer is assumed to be vertically homogeneous [19], and certain aspects are set as constants or are not considered, such as soil moisture [19], precipitation intensity [15], or vegetation characteristics [18].

In this study, we take a detailed modeling approach to evaluate green roof and cool roof performance compared to traditional roofs in terms of temperature, water consumption, and economic cost. We use MLCan, a multi-layer canopy model, which resolves the water and energy balance through coupled soil and vegetation layers $[20,21]$. We simulate intensive (deep soil layer) and extensive (shallow soil layer) green roof cases over a 72-day drought period over the spring and summer of 2012 in central Illinois, U.S.A. In terms of water consumption, we consider a dry study period as a worst-case scenario in terms of vegetation water stress and potentially high irrigation requirements. We simulate the effect of added irrigation on vegetation behavior, evaluating the benefit of irrigation as part of regular maintenance [5]. To model roof impacts on ambient and interior temperature, we also simulate traditional and cool roof cases using MLCan and compare green roofs, cool roofs, and traditional roofs in terms of surface temperatures and heat fluxes. The results of the temperature analysis show the effect of the surface reflectivity and insulating layers on both building energy requirements and the UHI effect. The results of the modeling analysis are integrated to perform a cost comparison of types of roofs in terms of installation, maintenance, and energy costs. 


\section{Materials and Methods}

\subsection{Study Site and Forcing Data}

We study the Business Instructional Facility (BIF) green roof at the University of Illinois at Urbana-Champaign which was installed in 2008 to satisfy requirements for LEED (Leadership in Energy and Environmental Design) platinum status. The roof is comprised of four monolithic vegetated beds that cover a total of $372 \mathrm{~m}^{2}$. Each of the beds contains nine species of sedums, herbaceous plants and native grasses. The planting medium depth is $20 \mathrm{~cm}$, and the roof is classified as intensive. However, the monolithic structure and lower maintenance needed for this roof means that it is further classified as "simple intensive". The planting medium is engineered highporosity LiteTop media with a water retention panel underneath. Sensors on the green roof measure air temperature $\left(T_{\text {air }}\right)$, relative humidity $(R H)$, wind speed $(U)$, and incoming radiation $\left(R_{g}\right)$ at a $2.2 \mathrm{~m}$ height, in addition to rainfall $(P P T)$ and volumetric moisture content $(\theta)$, all at 1-minute intervals. An additional conventional roof is located adjacent to and $4.3 \mathrm{~m}$ above the green roof. This conventional roof partially shades the green roof until about 10:00 a.m., causing lower than expected observed $R_{g}$ and $T_{a}$ in the early morning. Further details of the placement and calibration of the sensors can be found in [22].

We averaged the 1-minute data from the BIF green roof to 30 -minute intervals for simulations. We selected the dates of March 29 to June 11, 2012 (Julian Days of Year (DOY) 88-160) based on data availability and as an example of a particularly dry period. Several gaps in wind speed during the period were filled using bias-corrected hourly data from the National Oceanic and Atmospheric Administration (NOAA) at Champaign, Illinois [23]. Hourly atmospheric pressure $\left(P_{a}\right)$ data were obtained from North American Land Data Assimilation System (NLDAS) [24] forcing data for a grid point in central Illinois and interpolated to half-hourly for input forcing data.

We also referred to the BIF green roof setup for information on the vegetation types typically planted on an Illinois green roof as well as soil characteristics. For green roof simulations, we chose the plant Koeleria macarantha (prairie junegrass). This native grass species is used in many green infrastructure applications, including green roofs [12], and is one of the native grasses used on the BIF green roof. It is highly resistant to heat, cold, and drought, and has an average leaf area index $(L A I)$ of 3.6 [25] and an approximately vertical leaf distribution. In general, a higher $L A I$ leads to more latent heat flux and consequently more cooling of the roof. We chose 
an intermediate value to decrease water demand and be representative of the spring and early summer seasons.

\subsection{Ecohydrological modeling of green roofs}

Green roof simulations are performed using the vertically-resolved canopyroot-soil model, MLCan [20, 21]. The model incorporates explicit coupling between leaf-level ecophysiological processes (photosynthesis and stomatal conductance), physical processes (energy balance and boundary layer conductance), and below-ground states (soil water content and soil temperature) to capture interactions between soil, vegetation, and climate. MLCan incorporates both $\mathrm{C} 3$ and $\mathrm{C} 4$ photosynthetic pathways and resolves the vertical radiation, thermal, and environmental regimes within the canopy and soil-root systems. The model has been validated for both $\mathrm{C} 3$ and $\mathrm{C} 4$ vegetation $[20,26]$ and evaluated for its ability to capture acclimatory responses of vegetation to elevated $\mathrm{CO}_{2}[26,27]$.

In the above-ground system, MLCan resolves the short- and long-wave radiation regimes throughout the vertical canopy space. Radiation attenuation is in large part determined by the vertical distribution of foliage characterized by the leaf area density (LAD). MLCan provides predictions of photosynthetic $\mathrm{CO}_{2}$ assimilation and respiratory losses, as well as latent $(L E)$ and sensible heat $(H)$ fluxes for each canopy layer. This prediction is done through consideration of the energy balance for both sunlit and shaded leaf fractions. Water storage on foliage as a function of dew or rainfall interception is likewise considered.

In the below-ground system, soil moisture and soil heat are resolved throughout the vertical soil domain. While throughfall, soil evaporation, and plant transpiration provide the surface flux boundary conditions and sinks/sources for the soil moisture model, ground heat flux into the soil obtained from the surface energy balance sets the flux boundary conditions for the soil heat model. Variation of soil temperature at the surface and bottom of the soil profile over the course of the day is used to evaluate the efficacy of green roof strategies. For the soil moisture model, in addition to plant water uptake, hydraulic redistribution [28] is included to simulate the passive transport of moisture throughout the root and soil column following water potential gradients. In our simulations, thin soil layer discretization $(\sim 1 \mathrm{~cm})$ is used to accurately capture the distribution of temperature and moisture in shallow soil depth simulations. In addition, the efflux of $\mathrm{CO}_{2}$ from the soil surface is determined using a simple model to account for the known temperature dependence of soil respiration in the net carbon balance $[29]$. 


\subsection{Roofing Scenarios}

Extensive and intensive green roof conditions $(20 \mathrm{~cm}$ and $50 \mathrm{~cm}$ of planting media, respectively) were compared with traditional roofs and cool roofs (Figure 1). To simulate non-vegetated roof conditions, the MLCan model and forcings were adjusted to reflect extremely low $(\theta=0.01)$ soil moisture, no vegetation $(L A I=0)$, and no precipitation. This approximation assumes that there is no ponding on the roof, and that any evaporation of moisture would have a negligible effect of cooling of the roof surface. The soil reflectivity (albedo) was set to 0.95 to simulate a white (cool) roof, and 0.05 to simulate a black (traditional) roof. For comparison, the soil reflectivity of the green roof is set to 0.2 . However, the main drivers of reflectivity and energy balance partitioning for the green roofs are the moisture and vegetation conditions, which do not exist in the traditional and cool roof cases.

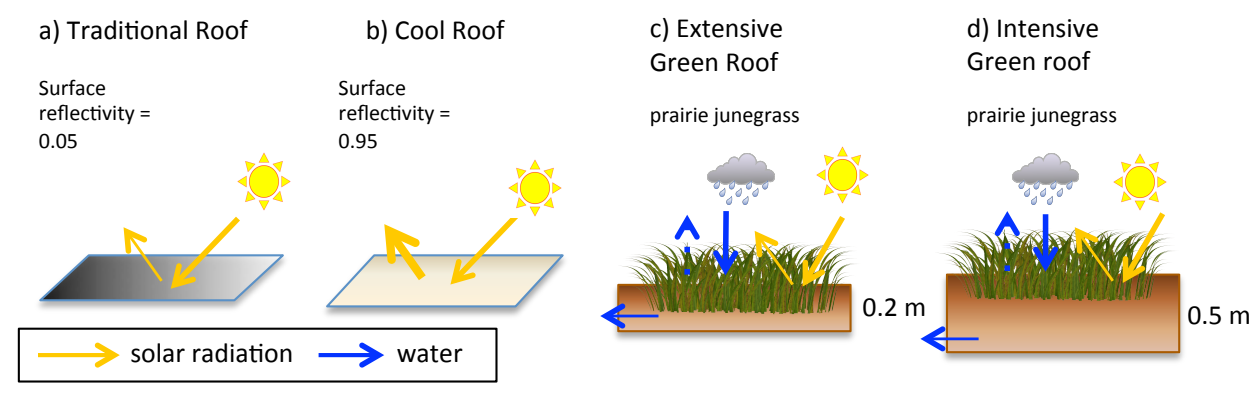

Figure 1: The four roofing strategies simulated using MLCan are (a) a traditional (black) roof, (b), a cool (white) roof, (c), an extensive green roof with $0.2 \mathrm{~m}$ soil layer, and (d) an intensive green roof with $0.5 \mathrm{~m}$ soil layer.

Most green roofs include both a high-porosity, high-conductivity planting medium to increase infiltration and a water retention panel underneath this layer to improve the unit's overall water storage properties. For the extensive and intensive cases, 20 and 50 soil layers were simulated, respectively. In the simulation, the top soil layer has a hydraulic conductivity of $12 \mathrm{e}-3 \mathrm{~m} / \mathrm{s}$ and has a slight exponential increase for deeper layers due to compaction and a free-flow bottom boundary. Due to lack of soil moisture data at multiple layers of the study green roof, we assume that this conductivity and boundary layer condition balance the effects of the porous planting medium, water retention panel, and roof drainage. To assess the need for irrigation during the study period, we simulated both extensive and intensive green roof cases with and without artificial irrigation. On days preceded by 
48 hours of dry conditions (no precipitation), $1 \mathrm{~mm}$ of precipitation was added between 6:00 a.m. and 6:30 a.m. (Figure 5a,b). This condition was met for 40 of the 73 simulated days, so that the total irrigation depth is 40 $\mathrm{mm}$ during the study period. Table 1 provides a summary of the different scenarios compared for this study.

Table 1: Summary of scenario properties

\begin{tabular}{ccccc}
\hline Roof type & $\begin{array}{c}\text { LAI } \\
{\left[\mathrm{m}^{2} / \mathrm{m}^{2}\right]}\end{array}$ & $\begin{array}{c}\text { Soil } \\
\text { reflectivity }\end{array}$ & $\begin{array}{c}\text { Soil depth } \\
{[\mathrm{m}]}\end{array}$ & Description \\
\hline $\mathrm{T}-1$ & 0 & 0.05 & 0.01 & Traditional (Black), no PPT, no irrigation \\
$\mathrm{T}-2$ & 0 & 0.95 & 0.01 & Cool (White), no PPT, no irrigation \\
$\mathrm{T}-3$ & 3.6 & 0.2 & 0.2 & Green extensive roof, PPT only \\
$\mathrm{T}-4$ & 3.6 & 0.2 & 0.2 & Green extensive roof, PPT and irrigation \\
$\mathrm{T}-5$ & 3.6 & 0.2 & 0.5 & Green intensive roof, PPT only \\
$\mathrm{T}-6$ & 3.6 & 0.2 & 0.5 & Green intensive roof, PPT and irrigation \\
\hline
\end{tabular}

\subsection{Roofing alternatives cost analysis}

To model the impact of multiple changes such as wall insulation, leakage and roofing on a building's interior climate, researchers often use complex software to model the impact of circulation and the heating, ventilation and air conditioning (HVAC) system on building temperatures [30]. However, in this study we solely focus on the detailed energy analysis of the rooftop obtained from this model. The modeling analysis provides bottom-of-soil (or, in the case of the traditional and cool roofs, rooftop) temperatures, and we estimate the amount of heat leaving or entering the building using a simple conductance model. The conductance model states that the heat flux into the building is determined by the thermal resistance (R-value) of the concrete and the insulation material, and the temperature difference between the bottom of the soil (or rooftop) and the desired internal building temperature. Based on this heat model, we estimate energy cost for building operation based on current pricing data and installation costs. This study assumes that the main factors that impact building temperatures are the type of roof and the depth of roof insulation, and that other factors such as energy leakage remain constant. The conductance model works to model the heat transfer into the top floor of the building. In other words, the study estimates the incremental change in the energy required to heat or cool the building due to different types of roofing without considering the complexities of modeling the building's internal HVAC system.

It is recommended that building temperatures be kept between $21{ }^{\circ} \mathrm{C}$ and $23{ }^{\circ} \mathrm{C}$ for occcupants' health and comfort [31]. The lower bound of 
this temperature range was selected as the desired building internal temperature. Most steel structure buildings have a corrugated metal roof deck surrounding a layer of insulation and covered with waterproofing. Green roofs have additional loadings associated with the dead weight of the soil layer and vegetation and the transient loads of any water stored in the soil [32]. Consequently, roof decks supporting green roofs often contain $7.6 \mathrm{~cm}$ of unreinforced medium strength concrete in addition to extra bracing beneath the deck. This depth of unreinforced concrete typically has an R-value (thermal resistivity) of $0.0461{ }^{\circ} \mathrm{C} \mathrm{m}^{2} / \mathrm{W}$ [33]. In comparison, a typical 2.54 $\mathrm{cm}(1 \mathrm{in})$ thick roof insulation unit has an $\mathrm{R}$-value of $0.31{ }^{\circ} \mathrm{C} \mathrm{m}^{2} / \mathrm{W}(6.0$ $\left.{ }^{\circ} \mathrm{F} \mathrm{ft}^{2} / \mathrm{W}\right)$; a typical $5.08 \mathrm{~cm}(2 \mathrm{in})$ unit has an $\mathrm{R}$-value of $0.62{ }^{\circ} \mathrm{C} \mathrm{m}^{2} / \mathrm{W}$ $\left(12.1^{\circ} \mathrm{F} \mathrm{ft}^{2} / \mathrm{W}\right)[34]$. Energy cost analyses were conducted for both the 2.5 $\mathrm{cm}$ and the $5 \mathrm{~cm}$ insulation on the green roof, cool roof and traditional roof to allow for comparison. R-values are additive for materials in series, allowing us to calculate the transmittance of heat from the bottom of the soil through both the concrete and insulation. This additivity allows us to consider the insulative properties of the composite design of the roof. A conductance model based on a simple 1-D heat flux equation can be used to solve for the power required to heat or cool the building, as shown in Equation 1. Other studies have shown that when only building roof characteristics are in consideration, this simplified approach gives an appropriate estimate of the building heat flux from the roof [35].

$$
Q=\frac{1}{R_{c}+R_{i}} \times A \times \Delta T
$$

in which $Q$ is the power required to heat or cool the building in each half-hour timestep in watts; $A$ is the area of the roof $\left(371.61 \mathrm{~m}^{2}\right.$ for the study site); $\Delta T$ is the difference in temperature $\left({ }^{\circ} \mathrm{C}\right)$ between the bottom-of-soil temperature $\left(T_{b}\right)$ and the desired indoor temperature of $21{ }^{\circ} \mathrm{C}$; and $R_{c}$ and $R_{i}$ are $\mathrm{R}$-values representing the thermal resistivity of the concrete and the insulation, respectively. As previously mentioned, for this analysis, $R_{c}=0.0461$ ${ }^{\circ} \mathrm{C} \mathrm{m} m^{2} / \mathrm{W}, R_{i}(2.5 \mathrm{~cm})=0.31{ }^{\circ} \mathrm{C} \mathrm{m}^{2} / \mathrm{W}$, and $R_{i}(5.1 \mathrm{~cm})=0.62{ }^{\circ} \mathrm{C} \mathrm{m}{ }^{2} / \mathrm{W}$. For the green roof, $\Delta T=T_{b}-21$; note that for the cool and traditional roofs, $T_{b}=T_{\text {surf }}$. To convert from watts $(\mathrm{W})$ to kilowatt-hours $(\mathrm{kWh})$ for each 30 -minute timestep, the power $(Q)$ was multiplied by a factor of $5 \times 10^{-4}$.

Real-time pricing data produced by U.S. energy company Ameren were used to generate hourly electricity prices for the time period of the MLCan simulations [36]. Because data were not publicly available for the 2012 time period, 2014 data were used as a reasonable representation of trends. Heating for the study area is typically provided by the Abbott Power Plant 
(a combined heat and power facility supporting the university campus), which predominantly uses natural gas to generate steam, but uses some coal during the winter [36]. Natural gas monthly pricing averages for March-June 2014 were obtained from the US Energy Information Administration (EIA) [37]. Based on typical values, we estimated the heating efficiency for the building HVAC system to be $75 \%$ and the cooling coefficient of performance (COP) to be 2.2 [30].

Green roof installation costs vary significantly, depending on the roofing structure, types of plants, and existing drainage. Installation costs start at $\$ 215 / \mathrm{m}^{2}$ for extensive green roofs [38][J. Bruce, personal communication, May 12th 2016] and $\$ 323 / \mathrm{m}^{2}$ for intensive green roofs [38][J. Bruce, personal communication, May 12th 2016], with an annual maintenance cost of $\$ 8 / \mathrm{m}^{2}$ [39]. However, maintenance costs might be higher depending on the vegetation types and other green roof properties, such as the type of planting media and rooftop drainage systems used [39]. Green roofs have a typical design life of 30-50 years, due to the protection that the vegetation and soil provide from physical and UV damage [38, 40-42]. For this study, we assumed an average green roof life-span of 40 years.

A typical (traditional) three-ply asphalt built-up roofing system costs $\$ 129 / \mathrm{m}^{2}$ and has a design life of 10 years [42] [J. Bruce, personal communication, May 12th 2016]. We anticipate that a typical cool roof installation using reflective paint will not cost significantly more than installing a traditional roof and will also have a similar design life. However, we conducted a sensitivity analysis to investigate the impact of installing a traditional/cool roof with a slightly higher up-front cost but a higher design life. A modified, more expensive, roofing system has a cost of $\$ 151 / \mathrm{m}^{2}$ and a design life of 20 years [42] [J. Bruce, personal communication, May 12th 2016]. Maintenance costs for both traditional and cool roofs are usually estimated at around $2 \%$ of the installation cost annually to ensure that the roof lasts for its full design life [43]. These prices, along with the calculated building energy costs, are used to determine an annualized cost associated with each of the roofing types considered over a 39-year period, assuming an average $3.5 \%$ annual interest rate [44]. A similar analysis was conducted using a $7 \%$ interest rate, with similar conclusions.

\section{Results and Discussion}

\subsection{Roof Temperature}

During the spring and early summer study period, the average peak air temperature $T_{\text {air }}$ is about $23{ }^{\circ} \mathrm{C}$ (Figure 2), with average night-time 
temperatures of $14{ }^{\circ} \mathrm{C} . T_{\text {air }}$ reaches a day-time peak of $35{ }^{\circ} \mathrm{C}$ near the end of the study period (Figure $3 \mathrm{~b}$ ) and a night-time minimum of $0^{\circ} \mathrm{C}$ early in the study period (Figure 3a). The green roof soil surface temperature is very similar for all cases; the extensive green roof with irrigation case is presented as an example (Figure 2). The variation of soil surface temperature $T_{\text {surf }}$ closely follows $T_{\text {air }}$, with $T_{\text {surf }}>T_{\text {air }}$ during the day and $T_{\text {surf }}<T_{\text {air }}$ at night. The cool (white) roof temperature remains on average about $4{ }^{\circ} \mathrm{C}$ below $T_{\text {air }}$ regardless of time of day. In contrast, the traditional roof $T_{\text {surf }}$ is nearly equal to $T_{a i r}$ at night, but is on average $25{ }^{\circ} \mathrm{C}$ higher than $T_{a i r}$ during the time of peak solar radiation (Figure 2).

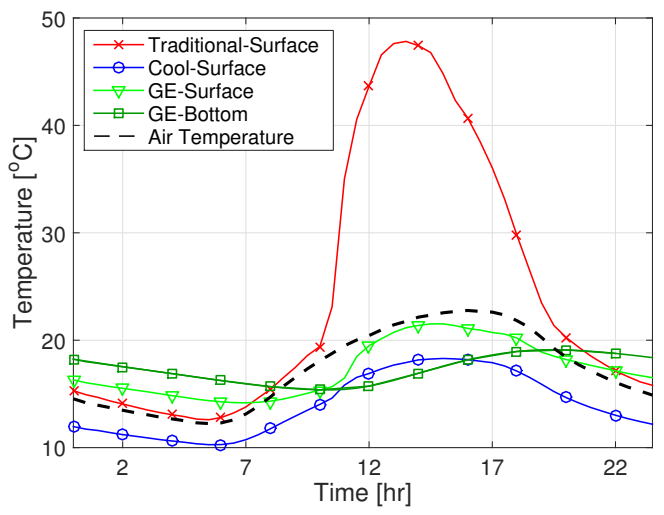

Figure 2: The average diurnal surface temperature for different roofing strategies compared to air temperature shows extreme heating of traditional roof surface compared to alternative roof types. The extensive green roof (GE-Bottom) bottom layer temperature indicates the insulating effect of the soil layers.

Particularly at the beginning of the study period in late March, the cool roof $T_{\text {surf }}$ is several degrees below $T_{\text {air }}$ (Figure $3 \mathrm{c}$ ). On rainy or cloudy days during this several day period, the traditional roof $T_{\text {surf }}$ is only slightly higher than $T_{\text {air }}$. On other days, the traditional roof $T_{\text {surf }}$ is up to 40 ${ }^{\circ} \mathrm{C}$ warmer than $T_{\text {air }}$ (Figure $3 \mathrm{c}, \mathrm{d}$ ). When considered over large surface areas, this temperature difference demonstrates the drastic effect that a non-reflective surface can have on the urban heat island effect.

We also consider the implications of roofing types in terms of building energy use. For the green roof cases, the bottom layer soil temperature dictates the necessary amount of building energy used for heating or cooling, notwithstanding any other layer of insulation. The soil depth dictates the damping and lagging of the diurnal $T_{a i r}$ signal. For the intensive $(0.5 \mathrm{~m}$ soil 

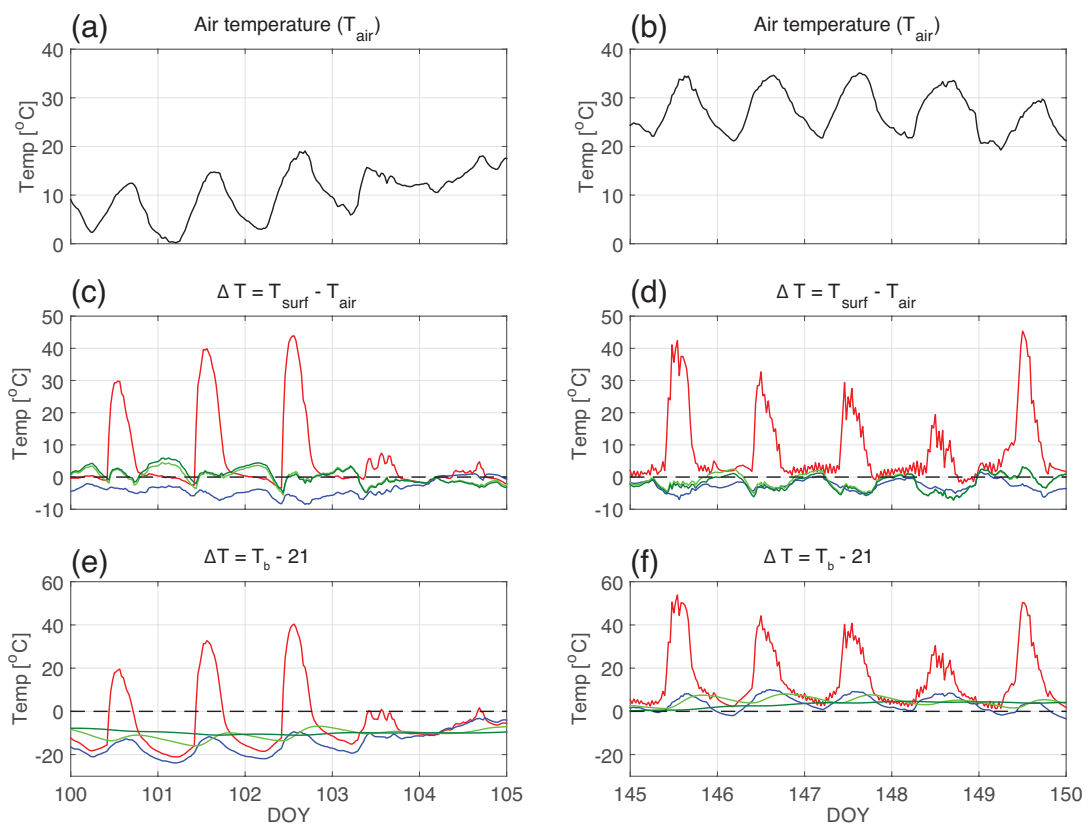

- Traditional_— Cool — Green Extensive — Green Intensive

Figure 3: Air temperatures during (a) coolest 5-day period (DOY 100-105) and (b) warmest 5-day period (DOY 145-150) illustrate the range of temperature conditions for green roof simulations. The difference between air and surface temperatures $(\Delta T=$ $\left.T_{\text {surf }}-T_{\text {air }}\right)$ for the different roof types during the coolest period (c) and the warmest period (d) show heating of the traditional roof surface, cooling of the cool roof surface, and maintenance of green roof temperature close to air temperature. The difference between roof bottom temperature and desired interior temperature of $21^{\circ} \mathrm{C}\left(\Delta T=T_{b}-21\right)$ for the coolest (e) period shows that traditional roofs require cooling during the day and heating at night, and cool roofs always require heating. During the warmest period (f), the traditional roof is always warmer than desired indoor temperature.

depth) green roof simulation, the diurnal temperature signal is extremely small at the bottom layer (Figure 3e,f). In general, the intensive green roof is a better moderator of indoor temperatures and energy consumption than the extensive roof due to the greater soil depth. However, a trade-off is the necessary structural support for the increased volume of soil in addition to the higher installation costs. The main difference between green roof cases in terms of temperature is due to the extensive and intensive soil depths, but the addition of irrigation caused slight decreases in soil temperature as well. 
This decrease is due to an increase in evaporative cooling, or $L E$, from the additional moisture, so that less heat is absorbed by the soil and transferred to the building. Compared to traditional and cool roofs, all green roof cases maintain soil bottom temperatures closer to $T_{\text {air }}$. During the coolest several day period of the study, cool roof temperatures are up to $20^{\circ} \mathrm{C}$ below the desired interior building temperature of $21^{\circ} \mathrm{C}$ (Figure 3e), indicating the need for additional heating or added insulation. Day-time traditional roof $T_{\text {surf }}$ is significantly higher than the building temperature even during cool periods near the beginning of the study. During warm periods, traditional roof $T_{\text {surf }}$ is $50{ }^{\circ} \mathrm{C}$ above the desired interior temperature (Figure $3 \mathrm{f}$ ).

In general, we see that the cool roof and green roofs behave similarly in terms of mitigating the UHI effect, maintaining $T_{\text {surf }}$ equivalent to or lower than $T_{a i r}$. Cool roofs most actively decrease the UHI effect, but surface temperatures are very low during cool periods, necessitating additional building heating, as described in Equation 1 [35]. A future avenue for roofing materials is the implementation of directionally reflective materials [45] that can absorb more heat when the sun angle is low to avoid excessive cooling. In contrast to cool and traditional roofs, green roof soil layers inherently provide an insulating layer, causing green roofs to be more efficient in terms of building heating and cooling. Both types of green roofs (intensive and extensive) are similar in terms of surface temperature but vary in terms of soil bottom temperatures due to the soil depths (Figure 3e,f).

\subsection{Green Roof Ecohydrology}

For the irrigated green roof cases, an increase in average diurnal $L E$ is observed starting at 6:00 a.m., the hour of irrigation addition on days preceded by dry periods (Figure 4a). The added water maintains the increased $L E$ through most of the day. This effect corresponds to reduced energy partitioning to $H$ (Figure 4,b). We see that irrigation serves to increase carbon uptake $(A n)$, indicating that the vegetation is functioning more optimally due to the added moisture (Figure 4c). Due to the previously mentioned shading effect until 10:00 a.m. on the green roof, we see low $L E, H$, and $A n$ in the early morning. The addition of irrigation does not appear to significantly impact surface or soil temperatures, but it is an important factor to consider in terms of the potential maintenance and water use required to ensure vegetation health during dry periods. For both irrigated and nonirrigated cases, $H$ is positive during the day, indicating that the surface is warming the atmosphere.

In addition to damping diurnal temperature variation and reducing the urban heat island effect, green roofs provide the benefit of reduced surface 

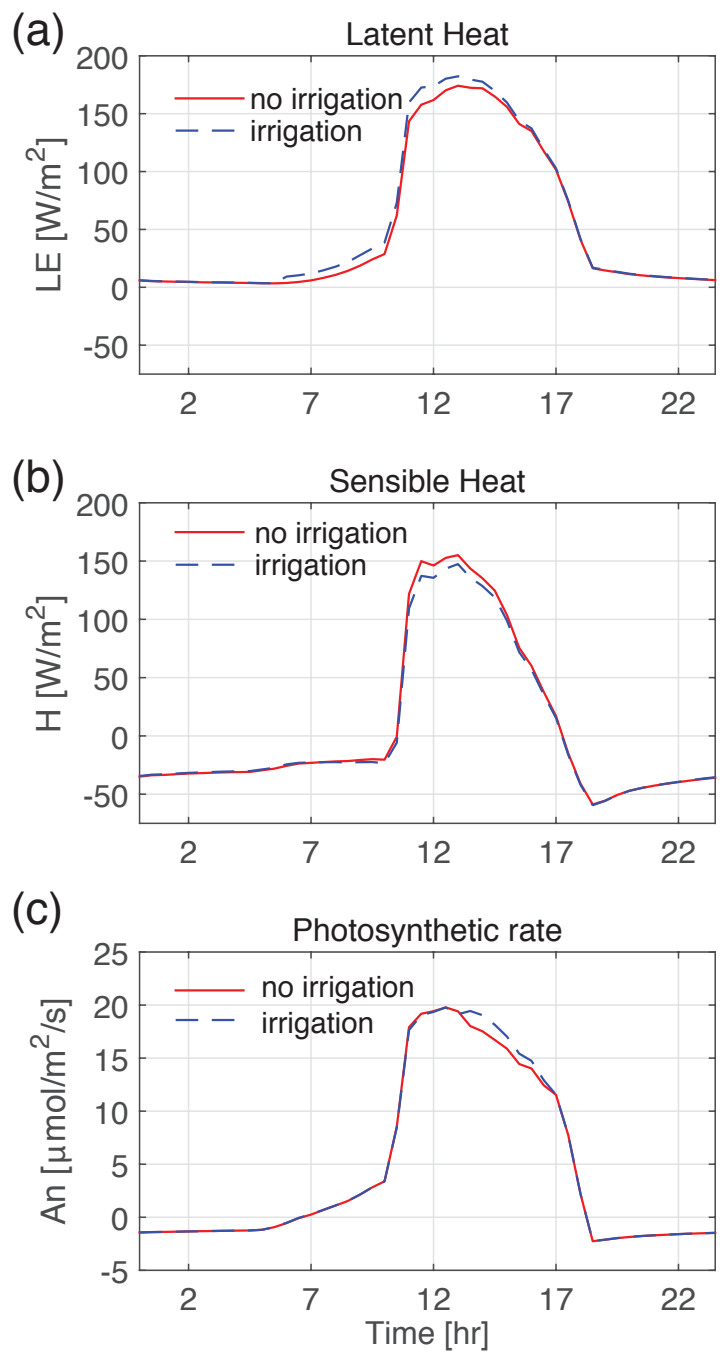

Figure 4: A comparison between non-irrigated and irrigated green roof simulation shows increased vegetation activity in irrigated cases through (a) increased diurnal latent heat flux $L E$, (b) decreased sensible heat flux $H$, and (c) increased photosynthetic rate during the afternoon hours.

runoff due to storage in the planting media and subsequent evaporation and transpiration. However, in non-irrigated cases, near surface soil moisture is extremely low during several days of the study, particularly for the extensive 

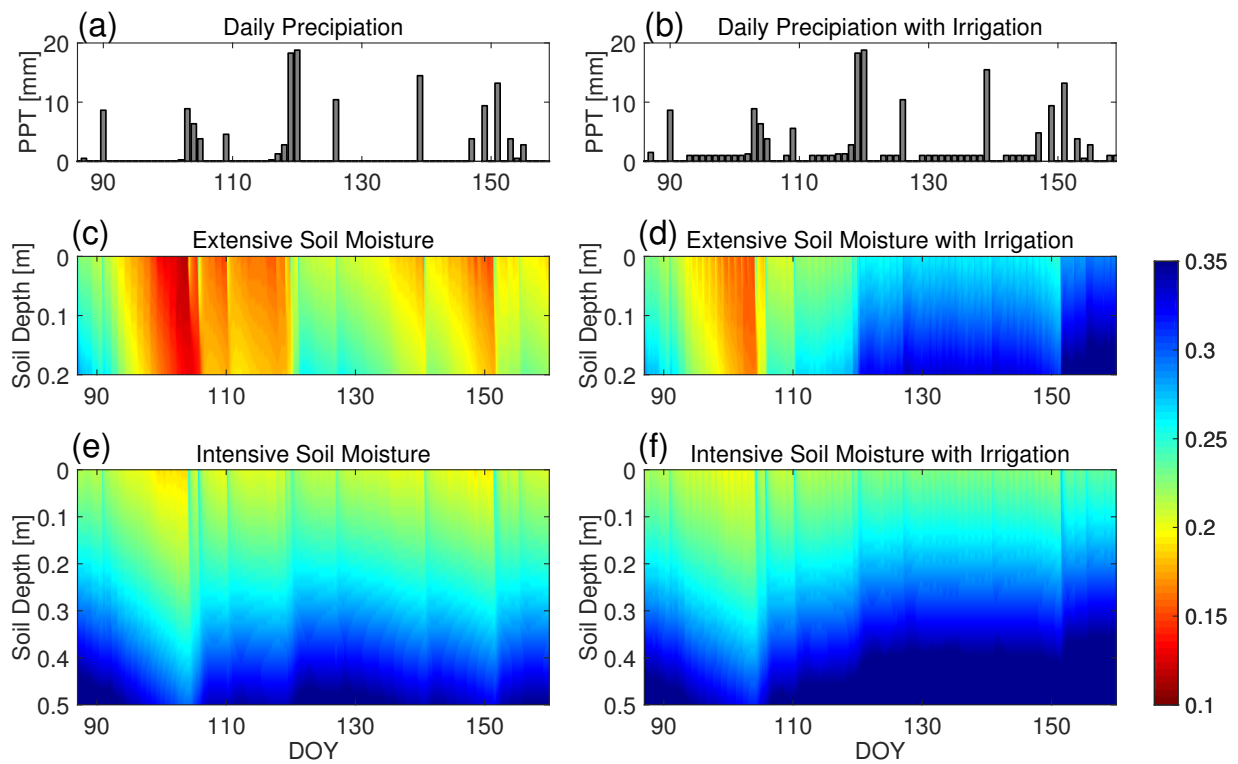

Figure 5: MLCan simulations were performed (a) without irrigation and (b) with $1 \mathrm{~mm}$ of irrigation during dry periods for both extensive and intensive green roof cases. (c) Extensive $(20 \mathrm{~cm}$ depth) green roof soil moisture $(\theta)$ is extremely low during dry periods without irrigation, and irrigation greatly increased soil moisture (d). Intensive $(50 \mathrm{~cm}$ depth) green roof soil moisture is higher throughout study period (e), and increased slightly with irrigation (f).

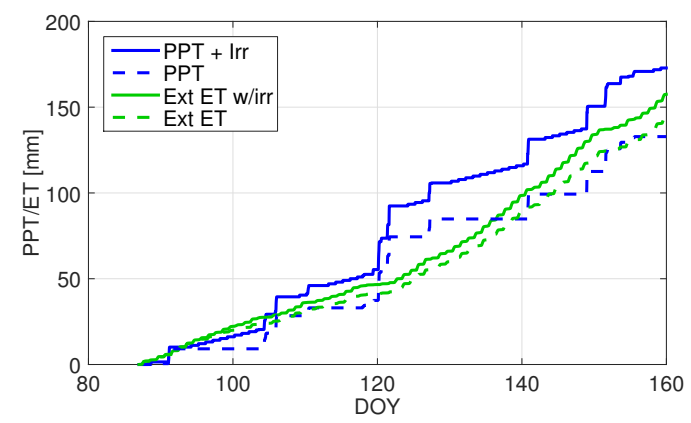

Figure 6: Cumulative precipitation $(P P T)$ and evapotranspiration $(E T)$ for irrigated and non-irrigated extensive green roof cases show increased $E T$ due to irrigation. The same increase in $E T$ was observed for the intensive roof simulation. 
green roof case (Figure 5c). For both green roof types, the addition of irrigation during dry periods increases soil moisture (Figure 5) and results in higher evapotranspiration (ET) than the non-irrigated case (Figure 6). Higher $E T$ and $A n$ for irrigated cases indicate improved vegetation health due to the irrigation. In terms of runoff reduction, we see that precipitation is retained in the soil layer to be evaporated from the soil or transpired by the canopy. In certain climatic regions, precipitation might be adequate for green roofs to thrive for most of the year, but the need for irrigation might constitute an added cost during dry periods. In certain regions, the additional cost of water should thus be included in the cost-benefit analysis.

\subsection{Roof Cost Analysis}

Table 2 shows the average daily heating and cooling costs associated with each of the roof types investigated with $2.5 \mathrm{~cm}$ thick roof insulation. Typically, the highest cooling costs are incurred on the traditional and cool roofs starting from late morning through mid-afternoon, peaking at around 3:00 p.m. Conversely, the highest cooling costs for the green roofs typically are lagged by around five hours, and peak at around 8:00 p.m. (Figure 7). All five of the alternative roofs show significant cost savings compared to the traditional roof, and the cool roof results in the least savings. The cool roof decreases the roof temperature significantly, eliminating cooling costs but increasing heating cost to maintain the desired interior temperature. Although the price of natural gas is an order of magnitude lower than the price of electricity, heating costs ultimately make the cool roof less cost-effective in terms of energy consumption than the green roof technologies. The highest energy cost savings are associated with the intensive $(0.5 \mathrm{~m})$ green roof. Irrigation does not make a large difference in cost savings, assuming that the cost of water is negligible compared to energy costs in Central Illinois. However, water consumption can be a significant limitation to green roof implementation in dry areas with high water costs. The most important factor in energy costs is the roof insulation, and we see that overall energy costs are almost halved by doubling the thickness of the roof insulation (Table 2).

In the case of the low-cost asphalt roofing, over the course of a 39-year timespan the intensive green roof has the highest annual cost, while the extensive green roof has the one of the lowest (Table 3). This discrepancy is due to the difference between the initial installation costs for the two types of green roofs. The cool roof shows significant savings in maintenance and energy costs compared to the green roofs. However, the recurring cost of replacing the cool roof every 10 years drives up the costs in the long-term. On the other hand, if the green roof scenarios are compared against the more 
Table 2: Average monthly energy cost savings for different roof types

\begin{tabular}{|c|c|c|c|c|c|c|c|c|}
\hline \multirow{2}{*}{ Roof type } & \multicolumn{2}{|c|}{ Heating Costs $[\$]$} & \multicolumn{2}{|c|}{ Cooling Costs $[\$]$} & \multicolumn{2}{|c|}{ Total Costs $[\$]$} & \multicolumn{2}{|c|}{$\Delta T C[\$]^{\dagger}$} \\
\hline & $2.5 \mathrm{~cm}$ & $5.0 \mathrm{~cm}$ & $2.5 \mathrm{~cm}$ & $5.0 \mathrm{~cm}$ & $2.5 \mathrm{~cm}$ & $5.0 \mathrm{~cm}$ & $2.5 \mathrm{~cm}$ & $5.0 \mathrm{~cm}$ \\
\hline $\mathrm{T}-1$ & 12.6 & 6.2 & 120.9 & 60.0 & 133.5 & 66.2 & - & - \\
\hline $\mathrm{T}-2$ & 23.0 & 11.4 & 9.3 & 4.6 & 32.3 & 16.0 & -101.2 & -50.2 \\
\hline $\mathrm{T}-3$ & 11.6 & 6.1 & 9.7 & 5.2 & 21.3 & 11.3 & -112.2 & -54.9 \\
\hline $\mathrm{T}-4$ & 11.5 & 6.1 & 10.1 & 5.4 & 21.7 & 11.5 & -111.8 & -54.7 \\
\hline $\mathrm{T}-5$ & 10.9 & 5.8 & 4.9 & 2.6 & 15.7 & 8.3 & -117.8 & -57.9 \\
\hline $\mathrm{T}-6$ & 10.7 & 5.7 & 5.1 & 2.7 & 15.9 & 8.4 & -117.6 & -57.8 \\
\hline
\end{tabular}

${ }^{\dagger}$ Difference in total cost from T-1

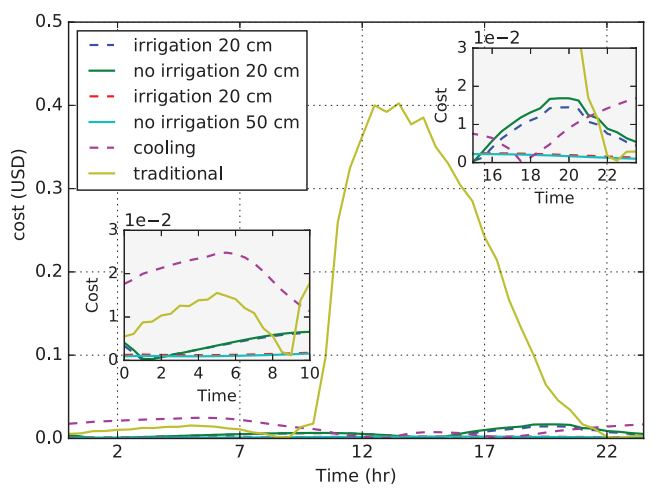

Figure 7: A plot of the diurnal average combined heating and cooling costs for traditional, cool, and green roof scenarios show costs that vary with time of day. The bottom inset highlights the higher cost for cools roofs (the pink dashed line) during the night. The top inset highlights the difference between the cool and green roof in the late afternoon.

expensive 20-year lifespan cool and traditional roofs, we see that the longlifespan cool roof is in fact the most cost effective alternative. This result is due to the higher maintenance costs of the green roofs - almost three times higher than the cool roof. Although the cost of the cool roof installation is higher, the green roof turns out to be more expensive overall. Comparing the annual costs between the roofs with $2.5 \mathrm{~cm}$ versus $5 \mathrm{~cm}$ insulation, we see that the added insulation has the greatest impact on the traditional roof, decreasing the annual cost by nearly $\$ 700$. 


\section{Conclusions}

Alternative roofing strategies are an attractive means of both mitigating environmental impacts and reducing costs. Table 4 summarizes key aspects of the comparison of traditional and alternative roofing techniques. On average, the traditional roof is $7{ }^{\circ} \mathrm{C}$ higher than $T_{\text {air }}$ and $3{ }^{\circ} \mathrm{C}$ higher than the desired interior temperature. Later in the summer these temperature differences are expected to be even higher. Cool roofs have the largest impact in terms of reducing roof temperatures and mitigating the urban heat island effect. As shown in Table 4, cool roof average temperatures are far below both $T_{a i r}$ and interior temperature and would be expected to be closer to interior temperatures as the summer progresses. However, the required building heating when the air temperatures are cooler leads to high overall energy costs compared to green roofs for the time period of study. The green roof temperatures are very close to $T_{a i r}$ and similar to the cool roof in terms of interior temperatures. The green roof soil layers provide an extra insulating layer that dampens diurnal variations in temperature. This additional temperature consistency leads to lower daily averaged cooling and heating costs. All alternative roofing strategies have lower average costs than the traditional roof, indicating the economic feasibility of any of these techniques.

The temperature reduction and damping of the diurnal temperature signal are particularly important in late spring/early summer when nighttime temperatures are still fairly low but daytime temperatures require some sort of cooling. The balance between heating and cooling is a significant annual cost, and it is advantageous to minimize the switching between heating and cooling. While natural gas prices are not currently increasing, it is nevertheless important for future economic sustainability to ensure that heating costs are not unnecessarily high.

In terms of other aspects of green roofs, the simulated green roof cases show the complete elimination of stormwater runoff from the rooftop. Note, however, that green roofs do not always elimate stormwater runoff for all storms, but rather delay and attenuate peak runoff. Since the study period is under a drought condition, we see improved green roof vegetation health and performance with the addition of irrigation. For the $372 \mathrm{~m}^{2}$ roof under consideration, $0.2 \mathrm{~m}^{3}$ of daily added water causes an average increase of 0.07 $\mathrm{m}^{3}$ of evapotranspiration and $0.06 \mathrm{~kg}$ of carbon uptake per day. The addition of irrigation also helps to decrease rooftop temperatures, but this effect is relatively small compared to the differences between roof techniques. Finally, we show in Table 4 that the carbon uptake of the green roof ecosystem 


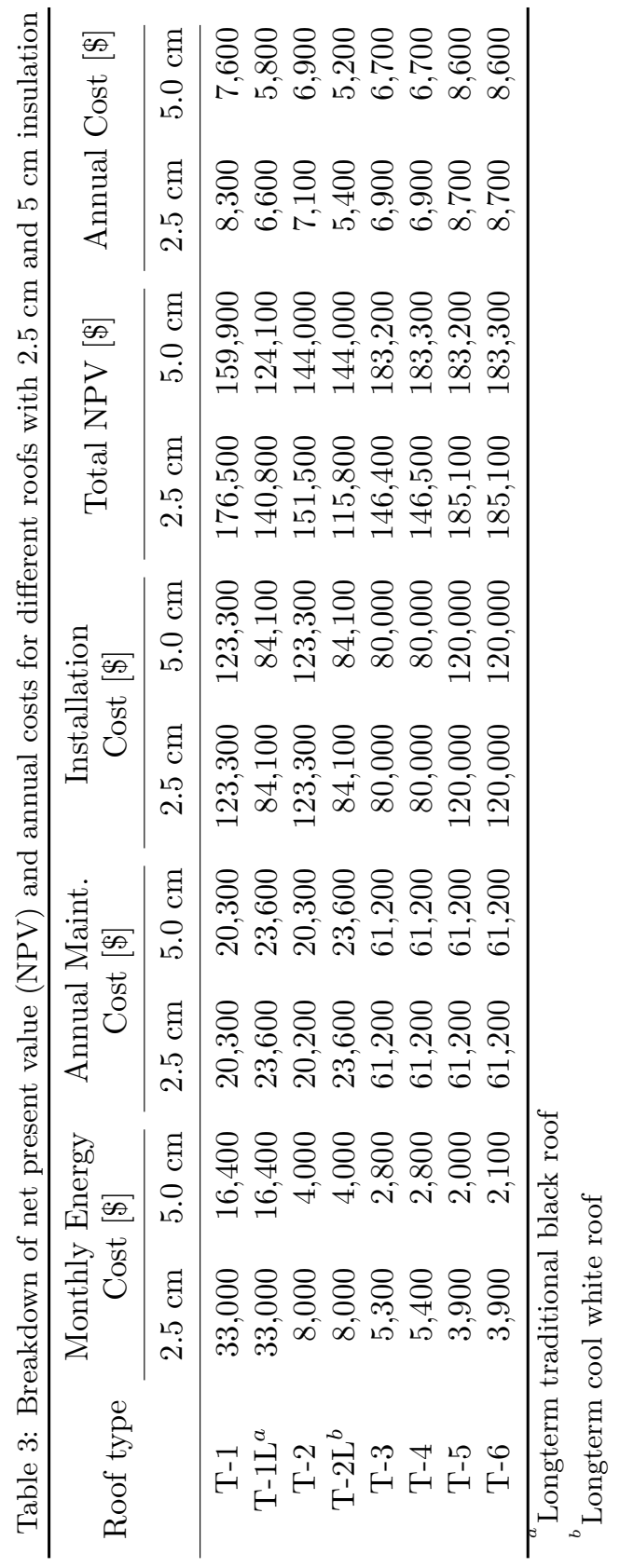


Table 4: Average Daily Statistics for $372 \mathrm{~m}^{2}$ roof

\begin{tabular}{|c|c|c|c|c|c|c|c|}
\hline \multirow{2}{*}{ Roof Type } & \multicolumn{3}{|c|}{ Water } & \multirow{2}{*}{$\begin{array}{l}\text { Carbon } \\
\text { Uptake } \\
{[\mathrm{kg} \mathrm{C} / \mathrm{d}]}\end{array}$} & \multicolumn{2}{|c|}{ Temperature $^{\dagger}$} & \multirow{2}{*}{$\begin{array}{l}\text { Cost } \\
\text { Daily } \\
\text { Total }[\$]\end{array}$} \\
\hline & $\begin{array}{l}\text { Runoff } \\
{\left[\mathrm{m}^{3} / \mathrm{d}\right]}\end{array}$ & $\begin{array}{l}\text { Irrigation } \\
{\left[\mathrm{m}^{3} / \mathrm{d}\right]}\end{array}$ & $\begin{array}{l}\mathrm{ET} \\
{\left[\mathrm{m}^{3} / \mathrm{d}\right]}\end{array}$ & & $\begin{array}{l}\bar{T}_{\text {surf }}-\bar{T}_{\text {air }} \\
{\left[{ }^{\circ} \mathrm{C}\right]}\end{array}$ & $\begin{array}{l}\bar{T}_{b}-21 \\
{\left[{ }^{\circ} \mathrm{C}\right]}\end{array}$ & \\
\hline $\mathrm{T}-1$ & 0.68 & 0.00 & - & - & 6.95 & 3.25 & 0.141 \\
\hline $\mathrm{T}-2$ & 0.68 & 0.00 & - & - & -3.29 & -7.00 & 0.016 \\
\hline $\mathrm{T}-3$ & 0.00 & 0.00 & 0.73 & 0.87 & 0.02 & -3.70 & 0.009 \\
\hline $\mathrm{T}-4$ & 0.00 & 0.20 & 0.80 & 0.93 & -0.02 & -3.74 & 0.008 \\
\hline $\mathrm{T}-5$ & 0.00 & 0.00 & 0.73 & 0.88 & 0.04 & -3.74 & 0.002 \\
\hline $\mathrm{T}-6$ & 0.00 & 0.20 & 0.80 & 0.94 & -0.02 & -3.80 & 0.002 \\
\hline
\end{tabular}

${ }^{\dagger} T_{\text {surf }}$ : Surface temperature

$T_{\text {air }}$ : air temperature

$T_{b}$ : temperature at bottom layer

is another significant environmental benefit, as rooftops might be one of the few opportunities for vegetated space in urban areas with high $\mathrm{CO}_{2}$ concentrations. Although the carbon uptake reported in this study represents an intermediate storage rather than long term sequestration, it has been found that green roofs can have significant sequestration benefits similar to native ground vegetation [46]. This study does not account for carbon losses due to plant die off during the winter and subsequent mineralization of litter or carbon loss due to drainage.

In general, roof insulation is important, regardless of which roofing type is selected. Roof insulation helps to dramatically reduce the energy consumption for heating or cooling the building. For example, doubling the thickness of a conventional commercial insulation essentially halves the cost of energy. A cool roof with the proper insulation might achieve similar heating and cooling costs to a green roof. However, the repeated roof replacement required for a standard cool roof in the long-term makes it less cost-effective than the extensive green roof. Upgrading the type of roof to one with a higher upfront cost increases the life time of the roof, and makes the upgraded cool roof the most cost-effective option, due to the high maintenance costs associated with the green roof. It should be noted, however, that our cost analysis does not monetize the other major benefits or detractors of green roofs such as runoff reduction, improved air quality, and additional water consumption via irrigation. Overall, both cool and green roofs provide significant economic and environmental benefits within urban environments. However, the choice of which roof type is most appropriate is highly location-specific and should be carefully considered, in order to maximize benefits while keeping costs low. 


\section{Acknowledgements}

Reshmina William was supported by funding from the UIUC CEE Distinguished Fewlloship and the Kinra Fellowship. Allison Goodwell is supported by NASA Earth and Space Science Fellowship \#NNX15AN55H. This research is partially supported by the NSF Grant \# EAR-1331906 for the Critical Zone Observatory for Intensively Managed Landscapes (IML-CZO), a multi-institutional collaborative effort.

\section{References}

[1] U.S. Green Building Council, Leadership in Energy \& Environmental Design Reference Guide, U.S. Green Building Council, 2003.

[2] United States Department of Energy, Cool roofs (2013). URL http://energy.gov/energysaver/articles/cool-roofs

[3] Center for Neighborhood Technologies (CNT), The value of green infrastructure: a guide to recognizing its environmental, economic and social benefits (Section 2.1).

URL http://www.cnt.org/repository/gi-values-guide.pdf

[4] U. Berardi, A. GhaffarianHoseini, A. GhaffarianHoseini, State-of-theart analysis of the environmental benefits of green roofs, Applied Energy 115 (2014) 411-428. doi:10.1016/j.apenergy.2013.10.047.

URL http://dx.doi.org/10.1016/j.apenergy .2013.10.047

[5] T. Sun, E. Bou-Zeid, G. H. Ni, To irrigate or not to irrigate: analysis of green roof performance via a vertically-resolved hygrothermal model, Building and Environment 73 (2014) 127-137. doi:10.1016/j.buildenv.2013.12.004.

URL http://dx.doi.org/10.1016/j.buildenv.2013.12.004

[6] A. Gagliano, M. Detommaso, F. Nocera, G. Evola, A multi-criteria methodology for comparing the energy and environmental behavior of cool, green and traditional roofs, Building and Environment 90 (2015) 71-81. doi:10.1016/j.buildenv.2015.02.043.

[7] M. Santamouris, Regulating the damaged thermostat of the cities: status, impacts and mitigation challenges, Energy and Buildings 91 (2015) 43-56. doi:10.1016/j.enbuild.2015.01.027. 
[8] A. Niachou, K. Papakonstantinou, M. Santamouris, A. Tsangrassoulis, G. Mihalakakou, Analysis of the green roof thermal properties and investigation of its energy performance, Energy and Buildings 33 (7) (2001) 719-729. doi:10.1016/S0378-7788(01)00062-7.

[9] G. Virk, A. Jansz, A. Mavrogianni, A. Mylona, J. Stocker, M. Davies, Microclimatic effects of green and cool roofs in London and their impacts on energy use for a typical office building, Energy and Buildings 88 (2015) 214-228. doi:10.1016/j.enbuild.2014.11.039.

[10] D. Yocca, Chicago City Hall Green Roof, Chicago, Illinois, accessed: 2015-08-06.

URL http://www.asla.org/meetings/awards/awds02/ chicagocityhall.html

[11] R. Nawaz, A. McDonald, S. Postoyko, Hydrological performance of a full-scale extensive green roof located in a temperate climate, Ecological Engineering 82 (2015) 66-80. doi:10.1016/j.ecoleng.2014.11.061.

URL http://linkinghub.elsevier.com/retrieve/pii/ S0925857414006570

[12] K. Getter, D. Rowe, Selecting plants for extensive green roofs in the United States, Michigan State University Extension Bulletin E-3047.

[13] N. Dunnett, N. Kingsbury, Planting green roofs and living walls (2nd ed.), Portland, Oregon: Timber Press.

[14] A. Nagase, N. Dunnett, Drought tolerance in different vegetation types for extensive green roofs: effects of watering and diversity, Landscape and Urban Planning 97 (4) (2010) 318-327. doi:10.1016/j.landurbplan.2010.07.005.

[15] C. Feng, Q. Meng, Y. Zhang, Theoretical and experimental analysis of the energy balance of extensive green roofs, Energy and Buildings 42 (6) (2010) 959-965. doi:10.1016/j.enbuild.2009.12.014.

URL http://dx.doi.org/10.1016/j.enbuild.2009.12.014

[16] P. Bevilacqua, J. Coma, G. Pérez, C. Chocarro, A. Juárez, C. Solé, M. De Simone, L. F. Cabeza, Plant cover and floristic composition effect on thermal behaviour of extensive green roofs, Building and Environment 92 (2015) 305-316. doi:10.1016/j.buildenv.2015.04.026.

URL http://www.scopus.com/inward/record.url?eid=2-s2.084929626478\\&partnerID=tZOtx3y1 
[17] R. Kumar, S. C. Kaushik, Performance evaluation of green roof and shading for thermal protection of buildings, Building and Environment 40 (11) (2005) 1505-1511. doi:10.1016/j.buildenv.2004.11.015.

[18] G. E. Harper, M. A. Limmer, W. E. Showalter, J. G. Burken, Ninemonth evaluation of runoff quality and quantity from an experiential green roof in Missouri, USA, Ecological Engineering 78 (2013) 127-133. doi:10.1016/j.ecoleng.2014.06.004.

URL http://dx.doi.org/10.1016/j.ecoleng.2014.06.004

[19] E. P. D. Barrio, Analysis of the green roofs cooling potential in buildings, Energy and Buildings 27 (2) (1998) 179-193. doi:10.1016/S03787788(97)00029-7.

[20] D. T. Drewry, P. Kumar, S. Long, C. Bernacchi, X. Z. Liang, M. Sivapalan, Ecohydrological responses of dense canopies to environmental variability: 1. Interplay between vertical structure and photosynthetic pathway, J. Geophys. Res. 115 (G4) (2010) G04022. doi:10.1029/2010jg001340.

[21] P. V. Le, P. Kumar, D. T. Drewry, J. C. Quijano, A graphical user interface for numerical modeling of acclimation responses of vegetation to climate change, Computers \& Geosciences 49 (2012) 91 - 101. doi:10.1016/j.cageo.2012.07.007.

[22] W. C. Holloway, N., A. Schmidt, Monitoring the hydrologic effects of an extensive green roof, Paper presented at World Environmental and Water Resources Congress 2009: Great Rivers, Kansas City, Missouri.

[23] NOAA National Centers for Environmental Information, Quality controlled local climatological data (2015).

URL https://www.ncdc.noaa.gov/data-access/land-basedstation-data/land-based-datasets/quality-controlled-localclimatological-data-qclcd

[24] NASA, Land Data Assimilation Systems (2015).

URL http://ldas.gsfc.nasa.gov/nldas/NLDAS2forcing.php

[25] A. Walker, A global data set of leaf photosynthetic rates, leaf $\mathrm{N}$ and $\mathrm{P}$, and specific leaf area (2014). doi:10.3334/ORNLDAAC/1224.

URL http://dx.doi.org/10.3334/ORNLDAAC/1224 
[26] P. V. V. Le, P. Kumar, D. T. Drewry, Implications for the hydrologic cycle under climate change due to the expansion of bioenergy crops in the Midwestern United States, Proceedings of the National Academy of Sciences 108 (37) (2011) 15085-15090. doi:10.1073/pnas.1107177108.

[27] D. T. Drewry, P. Kumar, S. Long, C. Bernacchi, X. Z. Liang, M. Sivapalan, Ecohydrological responses of dense canopies to environmental variability: 2. Role of acclimation under elevated CO2, J. Geophys. Res. 115 (G4) (2010) G04023. doi:10.1029/2010jg001341.

[28] G. G. Amenu, P. Kumar, A model for hydraulic redistribution incorporating coupled soil-root moisture transport, Hydrology and Earth System Sciences Discussions 4 (5) (2007) 3719-3769. doi:10.5194/hessd4-3719-2007.

[29] I. A. Janssens, K. Pilegaard, Large seasonal changes in q10 of soil respiration in a beech forest, Global Change Biology 9 (6) (2003) 911-918.

[30] E. Griggs, T. Sharp, J. MacDonald, Guide for estimating differences in building heating and cooling energy due to changes in solar reflectance of a low-sloped roof, 1989.

[31] American Society of Heating, Refrigerating, and Air Conditioning Engineers (ASHRAE), Standard 55-2013 - Thermal conditions for human occupancy (2010).

[32] Practice for determination of dead loads and live loads associated with vegetative (green) roof systems. doi:10.1520/e2397-11.

URL http://dx.doi.org/10.1520/e2397-11

[33] ISO:10456:2007, Building materials and products - hygrothermal properties - tabulated design values and procedures for determining declared and design thermal values, 2008.

URL http://www.iso.org/iso/catalogue_detail.htm?csnumber= 40966

[34] Carlisle Syntec Systems, 2014 Polyiso Insulation LTTR R-values.

[35] C. Clark, P. Adriaens, F. B. Talbot, Green roof valuation: a probabilistic economic analysis of environmental benefits, Environmental science \& technology 42 (6) (2008) 2155-2161.

[36] Ameren, Real time prices [data file]. URL https://www2. ameren.com/RetailEnergy/RealTimePrices 
[37] United States Energy Information Administration (EIA), U.S. price of natural gas delivered to residential customers [Data file].

URL http://www.eia.gov/dnav/ng/hist/n3010us3m.htm

[38] S. W. Peck, M. Kuhn, Design guidelines for green roofs, Ontario Association of Architects, 2009.

[39] US Environmental Protection Agency, Using green roofs to reduce heat islands.

URL http://www.epa.gov/heat-islands/using-green-roofsreduce-heat-islands

[40] E. Cubi, N. F. Zibin, S. J. Thompson, J. Bergerson, Sustainability of rooftop technologies in cold climates: Comparative life cycle assessment of white roofs, green roofs, and photovoltaic panels, Journal of Industrial Ecology.

[41] M. Blackhurst, C. Hendrickson, H. S. Matthews, Cost-effectiveness of green roofs, Journal of Architectural Engineering 16 (4) (2010) 136-143.

[42] A. Narayanan, R. Pitt, Costs of urban stormwater control practices, Tech. rep., University of Alabama, Department of Civil, Construction and Environmental Engineering (2006).

[43] K. Warseck, Roofing maintenance cost calculations, ASHRAE. URL http://www.facilitiesnet.com/roofing/article/RoofingMaintenance-Cost-Calculations-Facilities-ManagementRoofing-Feature--11896\\#

[44] Bankrate, Inc., Current mortgage rates. URL http://www.bankrate.com/finance/mortgages/currentinterest-rates.aspx

[45] H. Akbari, A. G. Touchaei, Modeling and labeling heterogeneous directional reflective roofing materials, Solar Energy Materials and Solar Cells 124 (2014) 192-210. doi:10.1016/j.solmat.2014.01.036.

URL http://linkinghub.elsevier.com/retrieve/pii/ S0927024814000555

[46] L. J. Whittinghill, D. B. Rowe, R. Schutzki, B. M. Cregg, Quantifying carbon sequestration of various green roof and ornamental landscape systems, Landscape and Urban Planning 123 (2014) 41-48. 